Transactions of the SDPS:

Journal of Integrated Design and Process Science

16 (3), 2012, 7-28

DOI 10.3233/jid-2012-0001

http://www.sdpsnet.org

\title{
Fundamentals of Design and Deployment of Large Complex Systems: OLEV, MH, and Mixalloy
}

\author{
Nam P Suh \\ President, KAIST, Daejeon, Korea
}

\begin{abstract}
A major task of engineering is the creation of innovative systems to solve societal problems. Yet many major corporations miss the delivery dates of their newly developed systems and exceed the originally estimated development cost. The likely reason for this is excessive reliance on experience and detailed analyses of sub-systems while ignoring the system-level design issues, especially the coupling of functional requirements (FRs) in the system architecture. A rigorous construction of system architecture and the use of a more formal, theory-based approach have led to systematic development and deployment of large complex systems at minimum cost within the allotted development time. In this paper, three case studies involving large, highly innovative systems are presented to demonstrate the power of rational design and system development: On-Line Electric Vehicle (OLEV), Mobile Harbor $(\mathrm{MH})$, and Mixalloy. The three systems presented in this paper were designed and developed based on axiomatic design theory. OLEV and MH were designed and deployed in two years at KAIST. Mixalloy, a dispersion-hardened $\mathrm{Cu} / \mathrm{TiB} 2$ alloy, was developed and commercialized in less than four years by MIT-connected colleagues near Boston; we created materials-processing techniques for the alloy, constructed the equipment and the factory for mass production, and sold the product. These three innovative systems were developed and deployed at minimum cost and on time because in each case the entire system was designed based on a firm theoretical foundation for system development and rigorous checking of the system architecture.
\end{abstract}

Keywords: complex system, axiomatic design, SMFIR, OLEV, MH, Mixalloy, independence axiom

\section{Introduction}

There have been many news releases suggesting the difficulty of designing and deploying large systems. Boeing had to delay the delivery of the Boeing 787 (the Dreamliner, which extensively uses graphite composites) for a few years because it had to fix some problems. Likewise, Airbus could not deliver its A380 on time. After being in service for a couple of years, these planes were grounded because problems had been discovered and had to be fixed. Also, the Rolls Royce jet engine used on the A380 had a problem. The devastating accident at the Fukushima nuclear power plants at the time of the 2011 earthquake and tsunami has been attributed to possible failure of cooling systems when the emergency electric power supply ceased to operate. In an entirely different field of human endeavor, it was recently

Corresponding author. E-mail: npsuh@kaist.edu / npsuh@mit.edu 
reported that the United States spent 17.9 percent of its GDP for healthcare and yet there are many people who do not get adequate access to medical service in the world's richest country. It is highly probable that the healthcare system is where the automotive industry was more than a half century ago in terms of the system design and robustness. Similarly, in Korea, an average family with children spends 20 to 30 percent of its income on private tutoring and for cram schools in order to increase the children's chances of getting into better universities. Yet, it is not certain that they are better educated - perhaps they are better trained in taking examinations - than those who do not get private tutoring. There are several common elements in all of these diverse examples. First, all of them appear to be large complex systems with many subsystems. Second, they have many functional requirements (FRs). Third, the systems appear to have had some design flaws. Fourth, the potential problems were not foreseen at the time of design and were not evident until the system ceased to function as intended. Fifth, it is highly probable that these systems are coupled systems, with coupling of FRs, violating the Independence Axiom. Sixth, all of these systems involve many different disciplines.

All of the systems mentioned in the preceding paragraph may be classified as complex systems (Suh, 2005, 2010a). Although companies must have hired many good engineers and managers to develop the systems, there were problems in the development. All of these problems must be attributed to the fact that the designers did not rigorously apply the basic theories of system design. Many companies might have relied on ad hoc approaches and experience-based knowledge when they undertook the system development. While experience and the analytical tools that were used are all very important in the development of these complex systems, one of the basic mistakes made by these firms might be related to selection of a wrong set of FRs and coupling of FRs that might have been corrected if it were known. However, many companies do not realize the existence of such problems until after the product is released.

Universities must also share the blame; they should do a better job of teaching the design of systems. Many universities do not teach basic theories of design and ignore the systems aspect of engineering altogether. One of the reasons for this is the educational background of engineering professors. Most of them tend to be specialists in analysis, who learned the reductionism of science and analysis. Some professors have not designed any product or had any experience in dealing with large systems. Although universities can readily remedy this situation, there is no driving force motivating them to do so.

The purpose of this paper is to present three case studies on the design and development of large complex systems. KAIST developed On-Line Electric Vehicle (OLEV) and Mobile Harbor (MH) (Suh, 2007, 2010c). A new start-up firm started by MIT people developed Mixalloy (dispersion strengthened alloy) and MuCell (microcellular plastics). These examples show that academia can develop complex systems in much shorter time than industry, using a theoretical foundation in system design. While in this paper three case studies are presented (OLEV, MH, and Mixalloy ${ }^{1}$ ), other large systems have also been developed based on the use of Axiomatic Design Theory.

Mixalloy was designed and developed by a start-up company near MIT from an idea -- without prior direct experimental trial of the Mixalloy process. Key participants were new to the production of metal alloys. Three young Ph.D.s ${ }^{2}$ (two mechanical engineers and a materials scientist) who had just received their doctorate degrees at MIT developed and commercialized Mixalloy with the help of about 30 engineers and technicians in a newly established small company near MIT. The product $\mathrm{Cu} / \mathrm{TiB}_{2} \mathrm{was}_{\text {sold }}$ as electrodes for spot welding machines used in automotive companies.

\footnotetext{
${ }^{1}$ In all four projects (OLEV, MH, Mixalloy, microcellular plastics), N. P. Suh was the inventor of the original idea and secured the necessary funding. He played indirect but active roles in executing all four projects. Many students and colleagues worked with him in developing these projects.

${ }^{2}$ Dr. J.H. Chun, now a professor at MIT, was the Vice President in charge of the entire operation, Dr. L.Sanchez and Dr. A.Lee were in charge of development. They worked together in all phases of the Mixalloy development from technology to business.
} 


\subsection{On design and development ${ }^{3}$ of engineering systems}

An engineering system typically must satisfy a set of functional requirements (FRs) within certain constraints (Suh, 1990, 2001, 2005). To satisfy the FRs, it may be necessary to decompose them into lower-level FRs, if there are no design parameters (DPs) that can satisfy the higher-level FRs. Then the system consists of many sub-systems, each of which satisfies a set of lower-level FRs. The complexity of the system, which is defined as a measure of uncertainty in satisfying the FRs (Suh, 2005), may increase with the total number of FRs and the number of layers of lower-level FRs. However, the complexity is small when the FRs are independently satisfied within the desired tolerances by designing an uncoupled or decoupled system, regardless of the number of FRs and the number of levels of decomposition required to complete the system ${ }^{4}$. The complexity of a system increases rapidly when the FRs, at any level, are coupled to other FRs. Coupled systems are not robust and may not work, requiring constant adjustment during operation. Therefore, designers should avoid coupling of FRs by making sure that the system is either uncoupled or decoupled (Suh, 1990, 2001), and this must be checked as the design process proceeds by constructing the system architecture of the entire system. Sometimes a DP at another branch of the decomposition may cause the coupling of the highest-level FRs. Thus, the task of checking for coupling requires a disciplined approach and organized effort by establishing the system architecture.

When the design of the entire system is uncoupled or decoupled, the system is robust and can readily be implemented. Such a system will work well from the beginning. However, many companies try to deal with coupled systems by employing more managers and by adding many additional layers of management rather than by solving the underlying problem caused by coupling of FRs. When these coupled systems are put into operation, they will not operate well and will continue to generate operational problems, requiring fine tweaking of the system. When they have coupled designs, companies typically go through many iterative processes, repeating the iterative cycle of design, fabrication, testing, re-design, fieldtesting, etc., but still that process may not function well when there is a basic design flaw due to coupling of FRs. This type of ad hoc management adds cost and prolongs the development time, yet many engineers and managers in industry think that it is quite normal in developing large complex systems. When the system architecture reveals that the system is a coupled design, it is best to redesign the system. This paper illustrates the power of checking the system architecture in order to spot coupling of FRs and eliminate them as they occur. The entire system must be free of coupling of FRs.

The question is: "Could coupling of FRs be eliminated from the beginning when the system has a large number of FRs and constraints?" The answer is "yes", if we check the system architecture from the early phase of the system design to be sure that FRs of the entire system and subsystems are not coupled. As a way of supporting this claim, three innovative complex systems will be presented here to show that when major mistakes are not made during the design and development stage, we can execute and deploy complex systems on time and at minimum cost.

OLEV (On-Line Electric Vehicle) (Suh et al., 2009; Suh, 2009b, 2009c; Suh et al., 2010; Suh et al., 2011; Suh, 2011a, 2011b, 2011d), MH (Mobile Harbor) (Suh, 2008, 2009a), and Mixalloy (Lee et al., 1988; Sanchez-Caldera et al., 1987; Sanchez-Caldera et al., 1990, 1991a, 1991b; Suh, 1981a, 1981b; Suh et al., 1982) are all very innovative large systems. OLEV was completed recently at KAIST and commercialized, all in two years from concepts to implementation. MH was also deployed in two years but is not yet commercialized. Mixalloy was developed and commercialized in less than four years by a start-up firm in Massachusetts, U.S.A. All three systems were free of coupling of FRs - they were all uncoupled or decoupled systems (Suh, 1990, 2001). For OLEV and MH, "system architecture teams" checked the system architecture by analyzing the decisions of groups designing subsets of the entire system.

\footnotetext{
${ }^{3}$ The same thought process has been used in designing other systems such as organizations, e.g., KAIST, Mechanical Engineering Department of MIT, and the Engineering Directorate of NSF.

${ }^{4}$ Axiomatic Design Theory has two axioms: the Independence Axiom and the Information Axiom. According to the Independence Axiom, all FRs must always be maintained independent from other FRs. The Information Axiom states that the design with less information content is a better design. (Suh, 1990, 2001).
} 
A project dealing with large systems must appoint a system architect (Lee \& Park, 2010) to oversee and control the overall system development. The management must make sure that the overall budget will be adequate to execute the project to completion. There are several routine things the designer/system architect has to do to develop a rational system, each one of which may appear to be somewhat mundane, but collectively they are powerful and absolutely necessary. Furthermore, if one of these steps is poorly done, the result will be devastating.

The system architect must be sure that the following sequence of design and development steps is followed rigorously (Suh, 2011c):

1) Who is the customer? What does the customer want? What is the problem? (These are some of the most difficult questions in developing a system.)

2) What is the complete set of the functional requirements (FRs) of the system, which must be satisfied to respond to the customer needs?

3) What are the constraints that the designed system must not violate?

4) How should the FRs be satisfied? What is the overall concept?

5) What are the design parameters (DPs) of the design that will satisfy the FRs? (It helps to sketch out the design concept when it involves hardware or organizations.)

6) Are these an acceptable set of DPs? Is the design matrix (that relates the vector $\{$ FRs $\}$ to the vector $\{$ DPs $\}$ ) diagonal or triangular? (If it is neither, go back and find another set of \{DPs $\}$ until the design at this level is uncoupled, i.e., diagonal matrix, or decoupled, i.e., triangular matrix.)

7) Decompose FR and DP if any chosen DP cannot be implemented because it is still conceptual and lacks details that can be implemented. (That is, find a set of lower-level FRs that can satisfy the higher-level FR.)

8) For each one of the lower-level FRs, find a DP by conceptualizing a design. Check for coupling of FRs.

9) Document the design by identifying and specifying the system architecture after each design decision is made. It will show the design hierarchy, i.e., design "tree", in terms of the FRs and DPs created. (This can be done readily using Acclaro, a software system specifically designed for this purpose.)

10) Proceed with the above outlined steps until the design is completed.

11) Draw the physical structure/shape, indicating the DPs on the drawings with a table of FRs that the DPs are chosen to satisfy.

12) Perform analyses to determine geometric dimensions or operating parameters for each $F R$ in terms of the DPs selected. (Note: If the design is uncoupled, each FR is a function of only one DP.)

13) Model the overall system to make the design robust. (For example, for $F R_{l}=A * D P_{l}$, if A can be made smaller, the design will be more robust, i.e., $F R_{l}$ can be satisfied within the required tolerance, even if $D P_{l}$ has a greater variation in operation. See (Suh, 2001) for further in-depth details.

14) Perform an experiment to determine the relationship between a given FR and DP, if the analysis may be too uncertain to be completely reliable. (Careful experiments are ultimately most reliable.)

15) Determine the sequence of operation, i.e., the sequence of changing DPs for the system to satisfy FRs, since many large systems tend to include some decoupled designs ${ }^{5}$ at lower-levels of FRs and DPs, which require sequential changes of DPs.

16) Periodically report to the customer the outcome of the design and development process.

\footnotetext{
${ }^{5}$ Decoupled design is represented by a triangular design matrix, i.e., $\{\mathrm{FRs}\}=\mathrm{A}\{\mathrm{DPs}\}$, where $\mathrm{A}$ is a triangular matrix. Therefore, DPs must be changed in a given sequence to avoid iteration to satisfy FRs. For an uncoupled design, A is a diagonal matrix and therefore, DPs can be changed in any order of sequence.
} 


\subsection{On system architecture to check for functional coupling for the entire system}

To check for the functional coupling during the design process, we can construct a system architecture, which can be done in many different ways (Lee \& Park, 2010). One way is to create a design matrix for all FRs-DPs, including all decomposed FRs and DPs. For example, consider the design given by the following FRs and DPs with two levels of decomposition:

$$
\left\{\begin{array}{l}
F R_{1} \\
F R_{2}
\end{array}\right\}=\left|\begin{array}{cc}
A_{11} & 0 \\
A_{21} & A_{22}
\end{array}\right|\left\{\begin{array}{l}
D P_{1} \\
D P_{2}
\end{array}\right\}
$$

$F R_{1}$ and $F R_{2}$ are decomposed as $\left\{F R_{11}, F R_{12}, F R_{13}\right\},\left\{F R_{21}, F R_{22}\right\}$ as

$$
\begin{aligned}
& \left\{\begin{array}{l}
F R_{11} \\
F R_{12} \\
F R_{13}
\end{array}\right\}=\left|\begin{array}{l}
X 00 \\
X X 0 \\
00 X
\end{array}\right|\left\{\begin{array}{l}
D P_{11} \\
D P_{12} \\
D P_{13}
\end{array}\right\} \\
& \left\{\begin{array}{l}
F R_{21} \\
F R_{22}
\end{array}\right\}=\left|\begin{array}{l}
X X \\
0 X
\end{array}\right|\left\{\begin{array}{l}
D P_{21} \\
D P_{22}
\end{array}\right\}
\end{aligned}
$$

One way of representing the system architecture for the above design -- represented by Eqs. (1), (2) and (3) -- is shown in Table 1.

Table 1. FR-DP design matrix table

\begin{tabular}{ccccccc}
\hline \hline & & \multicolumn{3}{c}{$\boldsymbol{D P}_{\boldsymbol{1}}$} & & \multicolumn{2}{c}{$\boldsymbol{D \boldsymbol { P } _ { 2 }}$} \\
\cline { 3 - 7 } & & $D P_{11}$ & $D P_{12}$ & $D P_{13}$ & $D P_{21}$ & $D P_{22}$ \\
\hline \multirow{4}{*}{$F R_{1}$} & $F R_{11}$ & $X$ & 0 & 0 & & \\
& $F R_{12}$ & $X$ & $X$ & 0 & 0 & \\
& $F R_{13}$ & 0 & 0 & $X$ & & \\
$F R_{2}$ & $F R_{21}$ & $A_{21}$ & & & $X$ & $X$ \\
& $F R_{22}$ & & & & 0 & $X$ \\
\hline \hline
\end{tabular}

It should be noted that the decomposition process deals with the diagonal elements. Therefore, we need to check whether the off-diagonal elements have unintended influence on other FRs. For example, at the highest-level, $D P_{2}$ was assumed to have no influence on $F R_{l}$. However, now that we have decomposed $D P_{2}$ into $D P_{21}$ and $D P_{22}$, the system architect (SA) or someone authorized by the SA should check whether $D P_{21}$ has any effect on $F R_{11}, F R_{12}$, and $F R_{13}$. (Similarly, $D P_{22}$ on $F R_{11}$, etc.) If so, the original decision that $F R_{1}$ and $F R_{2}$ are independent of each other (i.e., a decoupled design) is not correct. Then we need to go back and search for some other $D P_{21}$ and $D P_{22}$. When this is not done and if a mistake was made, the project will be set back by more than a year by the trial and error approach, because the coupled design will not work as intended. flaw.

If we had not constructed the system architecture, we would not have discovered this potential design

The system architecture becomes more complicated with the number of levels of decomposition. It is best to use commercial software such as Acclaro ${ }^{6}$.

\footnotetext{
${ }^{6}$ Product of Axiomatic Software Design, Inc.
} 


\subsection{Project description of on-line electric vehicle (OLEV)}

KAIST has established a goal of solving the most important problems of humanity in the 21st century -- those in the areas of energy, environment, water, and sustainability (EEWS) - as one of its institutional strategies (Suh, 2007).

OLEV was created to reduce the $\mathrm{CO}_{2}$ level in the atmosphere by replacing cars powered by internal combustion (IC) engines with emission-free electric vehicles (Pachauri, 2007). However, the batteries that power conventional electric vehicles (EV) have many shortcomings, i.e., high price, short life, and large weight and volume. The OLEV system uses electric power supplied externally. An underground power supply system both propels the vehicle and recharges a small battery on board (Suh et al., 2009; Suh, 2009b, 2009c; Suh et al., 2010; Suh et al., 2011; Suh, 2011a, 2011b, 2011d). The small battery enables OLEV to move autonomously on any road.

To conceive the OLEV system, the functional requirements (FRs) were defined together with constraints (Cs). After selecting the FRs, design parameters (DPs) were selected as per axiomatic design theory. The FRs and DPs were then decomposed to lower-level FRs and DPs. Throughout the design process, a "system integration team" checked the design at all levels for proper decomposition of the FRs and for inadvertent coupling of FRs when wrong DPs were chosen during the decomposition process. When it was found that the DPs violated the Independence Axiom (that coupling of FRs had been created by the chosen DPs), the design was modified to decouple or uncouple the FRs. Some of the problems encountered after the system was built and tested were due to missing FRs and constraints that were not considered at the time of design. For example, the FR related to maintenance of the temperature of the power pick-up unit of the OLEV system within an operating temperature range was not considered at the time of design. This missing FR caused a heating problem of the pick-up system, which was found after many hours of continuing operation of the OLEV system. This required a subsequent modification of the design.

The highest FRs for OLEV are defined as follows:

$F R_{1}=$ Propel the vehicle with electric power

$F R_{2}=$ Transfer electricity from the underground electric cable to the vehicle

$F R_{3}=$ Steer the vehicle

$F R_{4}=$ Brake the vehicle

$F R_{5}=$ Reverse the direction of motion

$F R_{6}=$ Change the vehicle speed

$F R_{7}=$ Provide the electric power when there is no external electric power supply

$F R_{8}=$ Supply electric power to the underground cable

The constraints are defined to be the following:

$C_{l}=$ Safety regulations governing electric systems

$C_{2}=$ Price of OLEV (should be competitive with cars with IC engines)

$C_{3}=$ No emission of greenhouse gases

$C_{4}=$ Long-term durability and reliability of the system

$C_{5}=$ Vehicle regulations for space clearance between the road and the bottom of the vehicle

The design parameters (DPs) are chosen as follows:

$D P_{1}=$ Electric motor

$D P_{2}=$ Power transfer device from the underground coil to the vehicle

$D P_{3}=$ Conventional steering system

$\mathrm{DP}_{4}=$ Conventional braking system

$D P_{5}=$ Electric polarity

$D P_{6}=$ Motor drive

$D P_{7}=$ Re-chargeable battery 
$D P_{8}=$ Electric power supply system (Inverter, etc. $)$

Note that in an ideal design the number of FRs and DPs must be the same (Theorem 4).

The design, as shown by the following design matrix in Eq. (4) is a decoupled design. Except that $F R_{l}$ is affected by $D P_{2}$ and $F R_{5}$ and $F R_{6}$ are affected by $D P_{1}$, it is almost an uncoupled design. Therefore, it is mostly one-input one-output design, which is easy to control. However, $F R_{2}$ cannot be controlled with $D P_{2}$ because $D P_{2}$ does not have sufficient details that can be implemented. $F R_{2}$ and $D P_{2}$ must be decomposed.

$\begin{array}{ccccccccc} & D P_{1} & D P_{2} & D P_{3} & D P_{4} & D P_{5} & D P_{6} & D P_{7} & D P_{8} \\ F R_{1} & X & X & 0 & 0 & 0 & 0 & 0 & 0 \\ F R_{2} & 0 & X & 0 & 0 & 0 & 0 & 0 & 0 \\ F R_{3} & 0 & 0 & X & 0 & 0 & 0 & 0 & 0 \\ F R_{4} & 0 & 0 & 0 & X & 0 & 0 & 0 & 0 \\ F R_{5} & X & 0 & 0 & 0 & X & 0 & 0 & 0 \\ F R_{6} & X & 0 & 0 & 0 & 0 & X & 0 & 0 \\ F R_{7} & 0 & 0 & 0 & 0 & 0 & 0 & X & 0 \\ F R_{8} & 0 & 0 & 0 & 0 & 0 & 0 & 0 & X\end{array}$

\section{Design of Disruptive Technology for OLEV: SMFIR}

$F R_{2}$ must be decomposed because the chosen $\mathrm{DP}_{2}$ for $F R_{2}$ needs more details to implement. The result is the Shaped Magnetic Field in Resonance (SMFIR), the technology that made OLEV possible. It transmits a large amount of electrical energy across empty space wirelessly and captures it at the other end by the receptor on the vehicle. To develop SMFIR, we started out with the FRs for OLEV. The SMFIR technology represents one of the most important aspects of OLEV systems.

$\mathrm{FR}_{2}$ and $\mathrm{DP}_{2}$ were stated as follows:

$F R_{2}=$ Transfer electricity from the underground electric cable to the vehicle

$\mathrm{DP}_{2}=$ Power transfer device from the underground coil to the vehicle

Since $F R_{2}$ cannot be implemented without further detailed design, $F R_{2}$ and $\mathrm{DP}_{2}$ must be decomposed.

The second level FRs obtained by decomposition of $\mathrm{FR}_{2}$ are as follows:

$F R_{21}=$ Create a magnetic field above the ground

$F R_{22}=$ Control the shape of the magnetic field

$F R_{23}=$ Control power level of the magnetic field

$F R_{24}=$ Pick up the energy of the magnetic field from the vehicle

$F R_{25}=$ Minimize the radiation of electromagnetic field, i.e., EMF

Fig. 1 shows the conceptual design that satisfies the $F R_{2 s}$.

The lower-level $D P_{2 s}$ are as follows:

$D P_{21}=$ Electromagnet design (ferrite core inside electric field)

$D P_{22}=$ Magnetic pole design $(L)$

$D P_{23}=$ Power level (strength) of the magnetic field 
$D P_{24}=$ Magnetic energy pick-up unit on the vehicle that is in resonance with the magnetic field $D P_{25}=$ Shield for stray electromagnetic field, i.e., EMF

The constraints that the design must not violate are the following:

$C_{l}=$ Maximum allowable EMF level of $62.5 \mathrm{Mg}$

$C_{2}=$ Maximum weight of the pick-up unit

$C_{3}=$ Electric shock resistance of the system

$C_{4}=$ Temperature rise should not exceed $20 \mathrm{C}$

$C_{5}=$ High magnetic permeability of the core material $m$

$C_{6}=$ Minimize the power loss

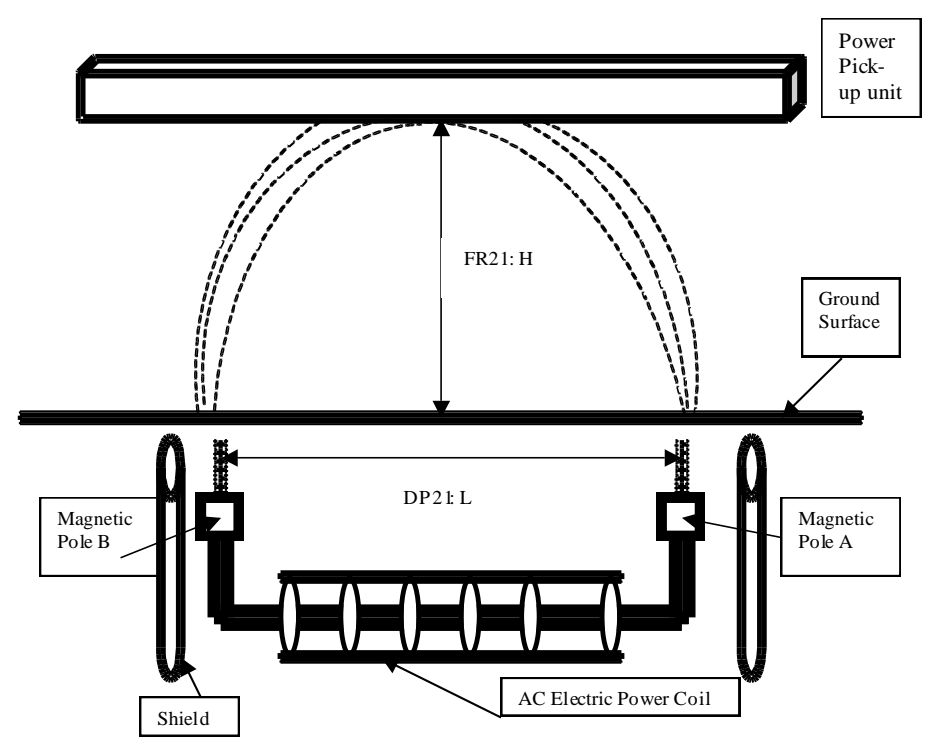

Fig. 1. Schematic drawing that shows the principle behind SMFIR.

As shown in Fig. 1, the magnetic field above ground is controlled by the underground power supply. The shape of the magnetic field characterized by the height $H\left(F R_{22}\right)$ is controlled by the distance between the two magnetic poles L. Thus $D P_{22}$, which controls $F R_{22}, H$, is $L$. The power level $\left(F R_{23}\right)$ is controlled by the amplitude of the current in the underground cable at a given voltage; thus $D P_{23}$ is the power supplied to the underground cable. The alternating magnetic field must be picked up, i.e., $F R_{24}$, by the pick-up unit mounted on the vehicle $\left(D P_{24}\right)$ at the frequency that resonates with the magnetic field generated from underground. To minimize the radiation of the magnetic field (EMF), i.e., $F R_{25}$, the system uses a shield embedded in the ground and an active and passive cancellation system mounted on the vehicle $\left(D P_{25 s}\right)$. This is the essence of Shaped Magnetic Field in Resonance (SMFIR) technology.

The design matrix for the $\mathrm{FR}_{2 s} / \mathrm{DP}_{2 s}$ is given by Eq. (5)

$$
\left\{\begin{array}{l}
F R_{21} \\
F R_{22} \\
F R_{23} \\
F R_{24} \\
F R_{25}
\end{array}\right\}=\left|\begin{array}{c}
X 0000 \\
X X 000 \\
X X X 00 \\
000 X 0 \\
X X X 0 X
\end{array}\right|\left\{\begin{array}{l}
D P_{21} \\
D P_{22} \\
D P_{23} \\
D P_{24} \\
D P_{25}
\end{array}\right\}
$$


The design is a decoupled design (Suh, 1990, 2001). Eq. (1) indicates that the DPs must be varied in the order given by the design matrix. According to Eq. (5) all DPs, except $D P_{24}$, affect the shielding of radiation.

The concept for OLEV was created to satisfy the following FRs: create a magnetic field above the ground, shape the field to reach the power pick-up unit mounted on the vehicle, control the strength of the field, and absorb the energy in the magnetic field by means of resonance (Suh, 2010b). We named this core technology the Shaped Magnetic Field in Resonance (SMFIR) (Suh, 2010b). Many participants developed the lower-level detailed designs under the direction of Professor D. H. Cho, Director of the OLEV Project. This proposed idea was checked and simulated by a team led by Professors J. H. Kim and Dr. S. Y. Ahn (Ahn et al., 2010). Professors D. H. Cho, C. T. Rim, and S. J. Jeon led the development of the underground power-supply system (Suh et al., 2011).

Many of these second level $F R_{2 s}$ must be decomposed further to develop more detailed designs of the SMFIR. For example, $F R_{24}$ and $D P_{24}$ must be decomposed to the next level to define the lower level $F R_{24 s}$ and $D P_{24 s}$. One possible way of decomposing $F R_{24 s}$ is as follows:

\section{$F R_{241}=$ Control the impedance of the pick-up coil to that of the incoming magnetic field \\ $F R_{242}=$ Control the natural frequency of the pick-up coil to match that of the magnetic field \\ $F R_{243}=$ Control the temperature of the pick-up coil within an acceptable range \\ $F R_{244}=$ Control the flow path of the magnetic field}

The DPs that can satisfy these FRs must be picked. Since the pick-unit must be designed using a coil and ferrite core, it may be characterized as an RLC circuit built inside a ferrite core. We may choose capacitance to satisfy $F R_{241}$, inductance to satisfy $F R_{242}$, a convective air channel for $F R_{243}$, and a shaped ferrite core for $F R_{244}$. There are many physical configurations and possibilities, all of which are variations of the basic idea described above. There are also many constraints at this level of design that cannot be violated.

The OLEV system installed in Seoul Grand Park in December 2009 is shown in Fig. 2. It replaced a noisy and smelly diesel system. The length of the circular path around the park is about $2.2 \mathrm{~km}$. The total length of the four segments of the underground power supply system is $372.5 \mathrm{~m}$. OLEV has a small battery on board to propel the vehicle even on roads without the embedded power system. The battery is recharged when the vehicle is on top of the road that has an underground power system. The system was designed so that the charge on the battery remains about the same after completing each round.

The input power to the underground system is $200 \mathrm{amps}$ at 440 volts and $20 \mathrm{KHz}$. This creates a magnetic field above the ground, which is shaped to reach the vehicle, controlling the distance between the magnetic poles in the ground. The maximum height of the magnetic field $H$ increases, when $L$ is increased. To maximize the power pick-up, the pick-up unit mounted on the vehicle is tuned to the frequency of the magnetic field. The power picked up is supplied to the electric motor at $60 \mathrm{~Hz}$ that drives the wheels of the OLEV and to the battery in d.c. to recharge. Two kinds of shielding for EMF are deployed: the one embedded underground and a passive cancellation system mounted on the vehicle. Sometimes an active shielding system is mounted on the vehicle. The EMF radiation from OLEV is well below the internationally specified level of $62.5 \mathrm{mG}$ at $20 \mathrm{kHz}$. The power supply is segmented so that only the segment directly below the vehicle is activated.

The SMFIR technology, which allows wireless transmission of a large amount of electric power, can be used in many other applications. They are being investigated at KAIST at this time.

Several OLEV systems - four buses, an SUV, a tram system, and the underground power supply system -- were designed, constructed, tested, and installed at KAIST, in the Seoul Grand Park, and at 2012 Yeosu Expo -- all in less than a year after the project was initiated. TIME magazine selected OLEV as one of "The 50 Best Inventions of 2010" (Time, 2010). The latest system at the Seoul Grand Park has been featured on an international broadcasting network (CNN, 2011). To conceive the OLEV system, the functional requirements (FRs) were defined together with constraints (Cs). After selecting the FRs, design 
parameters (DPs) were selected as per axiomatic design theory. The FRs and DPs were then decomposed to lower-level FRs and DPs.

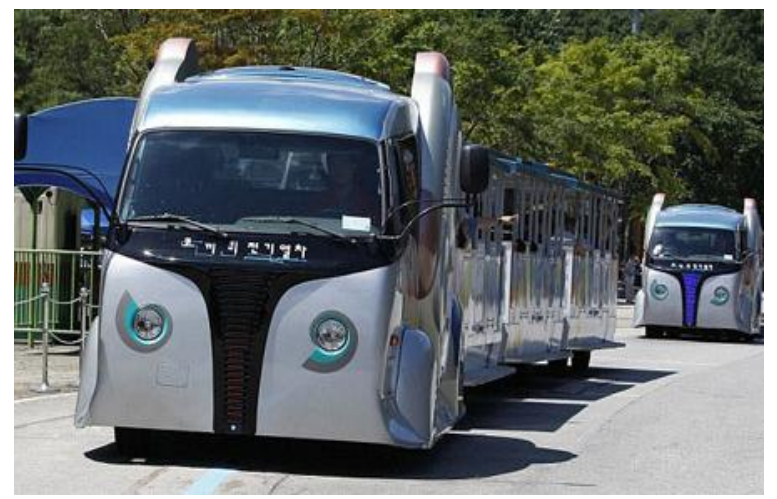

Fig. 2. OLEV Tram installed in Seoul Grand Park.

Throughout the design process, a "system integration team" checked the design at all levels for proper decomposition of the FRs and for inadvertent coupling of FRs when the DPs were chosen during the decomposition process. When it was found that the DPs violated the Independence Axiom (through creation of coupling of FRs by the chosen DPs), the design was modified to decouple or uncouple the FRs. Some of the problems encountered after the system was built and tested were due to missing FRs and constraints that were not considered at the time of design.

\section{Design and Development of Mobile Harbor (MH)}

The MH system was conceived when the author and his wife were visiting Singapore (Suh, 2008). There were approximately 100 ships outside the Singapore harbor, and it appeared that many of them were waiting for their turns to get into the harbor and unload their cargoes at the pier. This observation led to the idea of creating MH: "Why should the ships come into the harbor? Why not have the harbor go out to the ship?" The technical problem was transporting containers from a ship to the MH with precision while ocean waves and the strong wind in open sea keep the ship from being stationary. FRs were identified, and many alternate DPs were created, from which the final set of DPs were chosen for implementation (Suh, 2009a).

Mobile Harbor goes out to container ships moored in open sea, loads or unloads containers, and then delivers the containers to any harbor. MH solves several problems associated with ocean transportation and harbor management. As container ships become bigger, the Panama Canal is being enlarged and large harbors are being constructed to accommodate them. Each harbor may require $9 \mathrm{~km}$ of shore land, $20 \mathrm{~m}$ of deep water, and $\$ 3$ billion to construct. These vessels also require deep channels for navigation. $\mathrm{MH}$ will eliminate the need for large harbors. It will also reduce air pollution associated with ground transportation of containers from the large harbor to their final destinations, since $\mathrm{MH}$ can deliver goods at the nearest harbor, large or small, to the destination.

MH consists of a barge-like ship - its floating component - with its own engine and propelling system, and a crane that can reach containers in a large ship. It also has a control system that stabilizes the motion of the crane's end effector (the part that actually grabs and moves the container) to allow its precise movement even in rough seas with strong wind. A docking system enables $\mathrm{MH}$ to attach itself to the container ship for additional stability during loading and unloading of the containers (Kim et al., 2011). At KAIST, we have designed three different kinds of Mobile Harbor. After a 1:25 scale model for MH A1-125 was tested in a water basin with a wave generator, a large-scale MH was constructed and tested in rough sea (Reuter, 2011). 
A large team of engineers began the work on the Mobile Harbor Project at KAIST (Lee \& Park, 2010). They were assigned to develop various different parts of $\mathrm{MH}$. To be sure that the design of various components by different teams had not created unintended coupling of FRs, a team was assigned to check the system architecture.

The design of Mobile Harbor differs depending on its size. The bigger MH, such as A1-1200, is much more stable in comparison to the smaller MH A1-250, and therefore the design of the crane system for the larger $\mathrm{MH}$ is less elaborate.

The highest-level FRs for most MHs are as follows:

$F R_{I}=$ Moor the container ship in open sea

$F R_{2}=$ Move $M H$ with crane systems

$F R_{3}=$ Propel $M H$

$F_{4}=$ Stabilize $M H$ with a tall crane system

$F R_{5}=$ Dock MH against the container ship in open sea

$F R_{6}=$ Control the position of the end effector of the crane

$F R_{7}=G r a b$ the container using the end effector of the crane

$F R_{8}=$ Unload the container on $M H$ at the exact specified position

This $\mathrm{MH}$ project had two main design tasks. One is related to $F R_{5}$, which is related to mooring the $\mathrm{MH}$ against a container ship. The other is related to picking up and transporting the container from the container ship to the $\mathrm{MH}$. The important issues related to $F R_{6}, F R_{7}$, and $F R_{8}$ are: locating the container, sensing it, picking up the container, transporting it in rough sea where the containers and the crane are undergoing random motions, and placing it exactly where it should be located on the Mobile Harbor. A number of designs were considered (Kim et al., 2011).

Kim et al. (2011) came up with a design for $F R_{5}$ (Dock MH against the container ship in open sea with the following lower-level FRs:

$F R_{51}=$ Approach the $M H$ to the docking location

$F R_{52}=$ Prevent the ship from moving away from an intended location

$F R_{53}=$ Maintain relative distance between the $M H$ and the container ship

$F R_{54}=$ Minimize damage from a collision or contact between the MH and the container ship

$F R_{55}=$ Check environmental conditions

They chose the following $D P_{5 s}$ :

$D P_{51}=$ Azimuth thrusters, bow thrusters, and precise proximity maneuvering system

$D P_{52}=$ Anchor of container ship (one point mooring)

$D P_{53}=$ Robot arm mooring system

$D P_{54}=$ Adjustable fender system

$D P_{55}=$ Operation condition ( sea state and etc.) sensing / analysis system

The design at this level, $F R_{5}$, is shown to be a decoupled design.

$F R_{53}$ (Maintain relative distance between the $\mathrm{MH}$ and the container ship) had to be decomposed since $D P_{53}$ (Robot Arm Mooring System) cannot be implemented without further detailed design.

$F R_{531}=$ Attach the locking structure of the docking system to the outer hull of the container ship.

$F R_{532}=$ Lock the docking system to the ship within a certain distance.

$F R_{533}=$ Lock the docking system for various surface conditions (ship hull curvature, welding bead, moisture, and others)

$F R_{534}=$ Automatically subtract and contain/deploy, secure/release

$F R_{535}=$ Limit relative movements and relative distances during mooring 
The corresponding $\mathrm{DP}_{53}$ S are chosen to be the following:

$D P_{531}=$ Robot arm system

$D P_{532}=$ Sensor system for relative movement and relative distance

$D P_{533}=$ Vacuum suction pad system

$D P_{534}=$ Robot arm control system

$D P_{535}=$ Tension control winch mooring system (with mooring cables and fenders)

The design matrix was shown to be as follows (Kim et al., 2011):

$$
\left\{\begin{array}{l}
F R_{531} \\
F R_{532} \\
F R_{533} \\
F R_{534} \\
F R_{535}
\end{array}\right\}=\left\{\begin{array}{ccccc}
X & 0 & 0 & 0 & 0 \\
A_{21} & X & 0 & 0 & 0 \\
0 & 0 & X & 0 & 0 \\
A_{41} & A_{42} & A_{43} & X & 0 \\
0 & A_{52} & 0 & 0 & X
\end{array} \mid\left\{\begin{array}{l}
D P_{531} \\
D P_{532} \\
D P_{533} \\
D P_{534} \\
D P_{535}
\end{array}\right\}\right.
$$

This design was demonstrated to be extremely robust and effective in actual testing on open sea. In this design, the robot arm's function is to locate the vacuum pad on a surface of the ship that is relatively smooth. Then a vacuum is applied to firmly attach it to the ship. Then the robot arm becomes a flexible arm with minimum joint stiffness. The holding tension is force applied by the steel rope and controlled by a winch. The functions are beautifully uncoupled in this design.

We developed DPs and designed several MH systems; a version of MH A1-250 is shown in Fig. 3. (It was built on a barge to reduce cost.) Based on the specifications provided by KAIST, a contractor designed the floating structures of $\mathrm{MH} \mathrm{A1-1200} \mathrm{and} \mathrm{MH} \mathrm{A1-700,} \mathrm{which} \mathrm{were} \mathrm{certified} \mathrm{by} \mathrm{the} \mathrm{Korean}$ Register of Shipping. The smallest MH is A1-250. The KAIST MH Team designed the crane system for the smallest $\mathrm{MH}, \mathrm{A} 1-250$, that can operate precisely in rough sea. Other loading and unloading systems were also considered (Yang et al., 2009).

The end effector of the crane is automatically controlled to locate the container at pre-determined positions by cancelling the random motion caused by the waves and wind. It has sensors that can locate the position of the containers relative to the specified positions on the ship and MH. The specifications of all three MHs are given in Table 2.

It appears that there are many applications of the $\mathrm{MH}$ technology. In addition to transporting containers, the docking system can be used in many other applications. The robotic technology for crane control can be used in moving ladles in steel mills and other applications.

Table 2. Overall specification of $\mathrm{MH}$ A1-250, $\mathrm{MH}$ A1-700, and MH A1-1200

\begin{tabular}{llll}
\hline \hline & A1-250 & A1-700 & A1-1200 \\
\hline Length, O.A. & $76.75 \mathrm{~m}$ & $164 \mathrm{~m}$ & $164 \mathrm{~m}$ \\
Breadth & $33 \mathrm{~m}$ & $31 \mathrm{~m}$ & $41 \mathrm{~m}$ \\
Design draft & $5.3 \mathrm{~m}$ & $5.4 \mathrm{~m}$ & $5.7 \mathrm{~m}$ \\
Container capacity & $252 \mathrm{TEU}$ & $702 \mathrm{TEU}$ & $1,248 \mathrm{TEU}$ \\
Handling capacity & $60 \mathrm{TEU} / \mathrm{hr}$ & $60 \mathrm{TEU} / \mathrm{hr}$ & $120 \mathrm{TEU} / \mathrm{hr}$ \\
Speed & $8 \mathrm{knots}$ & $15 \mathrm{knots}$ & $12 \mathrm{knots}$ \\
\hline \hline
\end{tabular}



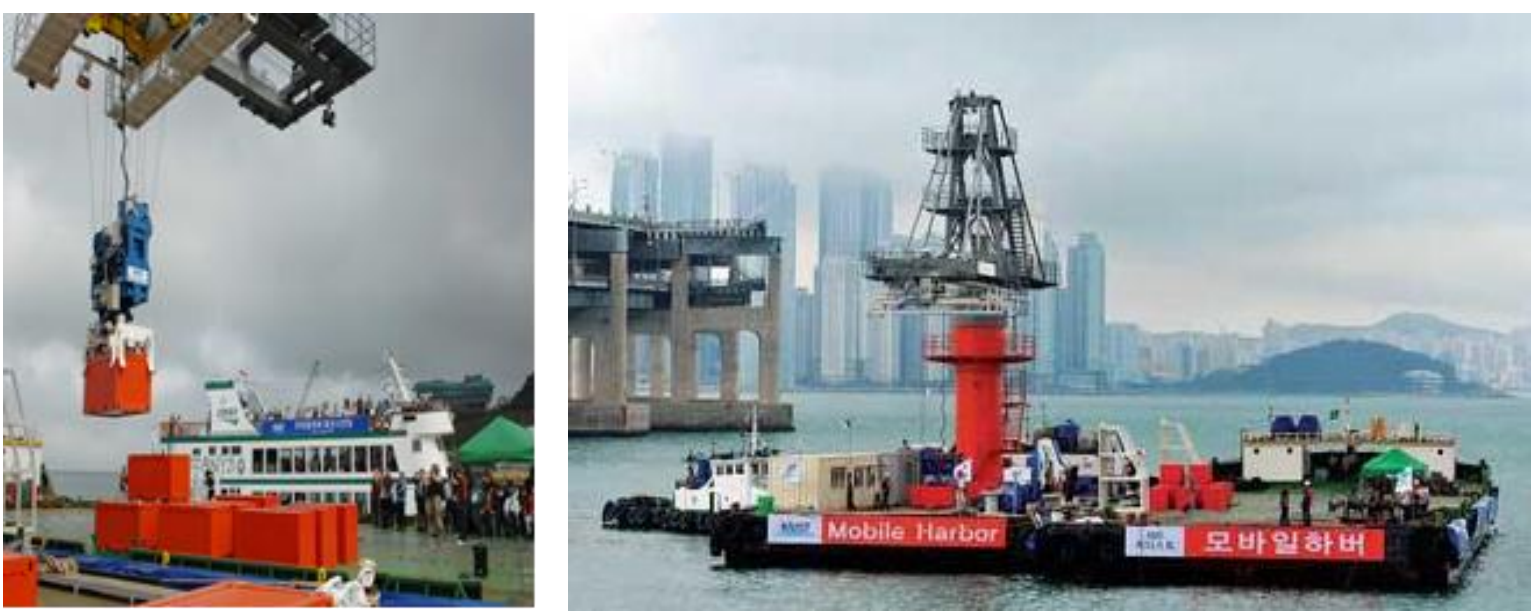

Fig. 3. 1/3 scale mobile harbor A1-250 developed at KAIST.

The picture on the left shows the crane/spreader transporting the container. The picture at the right shows the mobile harbor anchored to a barge, which replaced the actual ship in this demonstration to reduce the cost of demonstration. (The specifications of the MH shown are as follows: dimensions $=24 \mathrm{~m}$ (Boom length) X $3.3 \mathrm{~m}$ (Boom width) $X 19.6 \mathrm{~m}($ Height$)$; total weight $=125 \mathrm{ton}$; hoisting capacity $=4.5$ ton (working load), speed $=42 \mathrm{~m} / \mathrm{min}$; traveling stroke $=7.8 \mathrm{~m}(5.2 \mathrm{~m} \sim 13 \mathrm{~m})$, speed $=72 \mathrm{~m} / \mathrm{min}$; traversing stroke $=1$, traversing speed $=72 \mathrm{~m} / \mathrm{min}$; and slewing specifications, slewing angle $=280$ and slewing speed $=0.5 \mathrm{rpm}$.)

\section{Design, Development, and Commercialization of Mixalloy}

The Mixalloy, the process of manufacturing it, the equipment, and the factory for mass production were developed in three years. It was presented in (Suh, 1981a, 1981b, 2001). Therefore, only a brief review of the project will be given here.

To develop new materials based on Axiomatic Design, we proceed from the desired performance of materials specified in the customer domain to the desired material properties, FRs (properties), in the functional domain. Then, from the functional domain, we specify the microstructure in terms of design parameters (DPs). Having specified the DPs, we proceed to the process domain to develop processing techniques (PVs) that will yield the desired DPs.

The goal of the project was to make dispersion-strengthened copper alloy that has superior properties at high temperatures and can be used as spot-welding electrodes in welding automobile bodies. The desired performance characteristics are high strength at high temperatures (i.e., resistance to deformation), long life (i.e., resistance to wear), ease of formability, and toughness.

The FRs of Mixalloy may be stated as:

$F R_{I}=$ High strength at high operating temperatures $=\tau_{s}$

$F R_{2}=$ High elongation and toughness $=K_{c}$

$F R_{3}=$ High electrical and thermal conductivity $=f$

We can readily design the microstructure of the desired material that can satisfy the above FRs in terms of dispersion strengthened alloy. Fig. 4 shows the microstructure of an alloy that consists of pure phase (matrix phase) and small ceramic particles that are thermally stable. To increase the strength of copper, we can disperse a large number of thermally stable sub-micron ceramic particles in copper so as to block the motion of dislocations that are responsible for plastic deformation. Then, we can control the distance between dispersoids, $\lambda$, to control $F R_{l}$, the diameter of dispersoid, $d$, to control the toughness and elongation of the material, and the property of the metal matrix to control the conductivity. To have 
the required high conductivity, the matrix phase of the material must be pure, free of alloying elements. Therefore, the purity of the matrix $\phi$ may be chosen as $D P_{3}$.

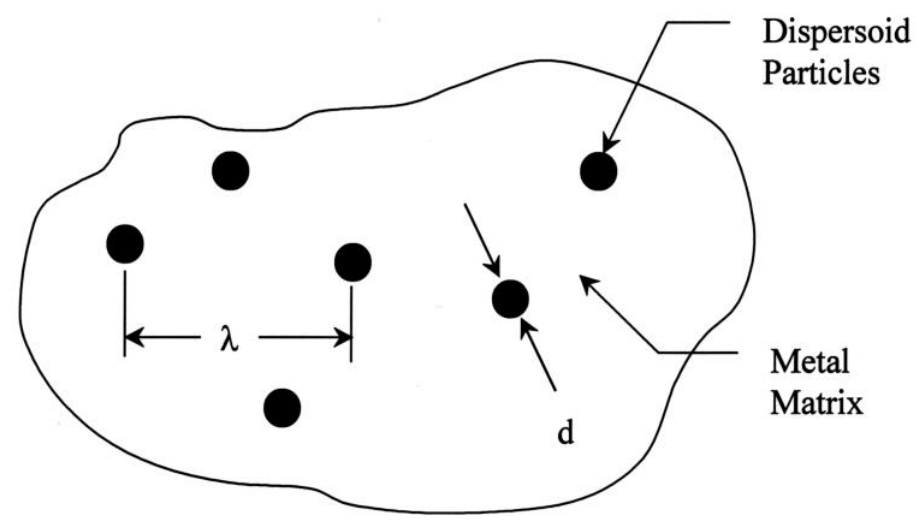

Fig. 4. Microstructure of dispersion strengthened copper with hard ceramic particle.

Then, the design equation for FR and DP may be written as

$$
\left\{\begin{array}{c}
\tau_{s} \\
K_{c} \\
\sigma
\end{array}\right\}=\left|\begin{array}{ccc}
X & 0 & x \\
0 & X & 0 \\
0 & 0 & X
\end{array}\right|\left\{\begin{array}{l}
\lambda \\
d \\
\phi
\end{array}\right\}
$$

The small $\mathrm{x}$ indicates that the alloying element has a relatively small effect on the strength of the matrix. We chose titanium and boron to make $\mathrm{TiB}_{2}$ dispersion-strengthened copper. Eq. (7) suggests that we can set the value of particle size $d$ first, before deciding on the distance between the particles. Since the manufacturing process often determines the size of the hard particles, the volume fraction of the hard phase can be used as $D P_{2}$.

To create the microstructure shown in Fig. 4, we developed the Mixalloy process (Lee et al., 1988; Sanchez-Caldera et al., 1987; Sanchez-Caldera et al., 1990, 1991a, 1991b; Suh, 1981a, 1981b; Suh et al., 1982). The idea is shown in Fig. 5. It consists of two reservoirs of molten metals, one with molten copper with a small amount of titanium and the other with molten copper with a stoichiometric ratio of boron. These molten metal streams are made to mix when they collide in an impingement-mixing chamber at high speeds because of the turbulent motion of the molten metals. Turbulent motion creates turbulent eddies. Tucker and Suh (1980) have shown that the size of the dispersoids is a function of Reynolds number $\mathrm{Re}^{-3 / 4}$. When sub-micron size eddies are created, the diffusion of titanium and boron occurs, and they react to form thermally stable atomic scale $\mathrm{TiB}_{2}$ in the molten stream. These dispersoids will grow if left at high temperature. To control the size of the dispersoids, we will have to quench the molten copper with tiny $\mathrm{TiB}_{2}$ dispersoids. To control the particle size, we must quench the material quickly so as to prevent the agglomeration and growth of $\mathrm{TiB}_{2}$ particles in the molten copper.

The DP/PV design equation for the Mixalloy process may now be written as

$$
\left\{\begin{array}{l}
\lambda \\
d \\
\phi
\end{array}\right\}=\left|\begin{array}{lll}
X & 0 & x \\
0 & X & 0 \\
0 & 0 & X
\end{array}\right|\left\{\begin{array}{c}
\text { Sol.Fract.ofTiandb } \\
\text { Rapidsolidification } \\
\text { Metringoftwostreams }
\end{array}\right\}
$$




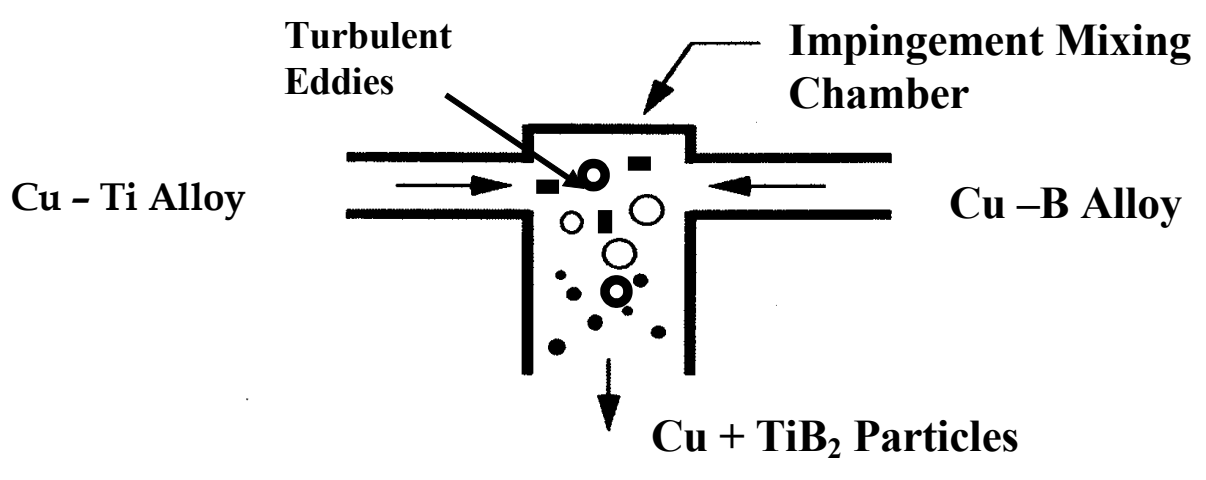

Fig. 5. Mixalloy process for making dispersion-strengthened alloy. This figure shows impingement mixing of $\mathrm{Cu} / \mathrm{Ti}$ liquid solution with $\mathrm{Cu} / \mathrm{B}$ liquid solution to form a pure copper phase with nano-scale titanium diboride particles.

The above design is a decoupled design. The metering ratio affects the volume fraction of $\mathrm{TiB}_{2}$. Although the above process is designed well to this level, we must develop the process further to be sure that we can achieve the design as stipulated by Eq. (8). We used rapid cooling of two molten streams to obtain a pure matrix phase and small dispersoids to prevent coarsening of hard $\mathrm{TiB}_{2}$ particles (Fig. 6).

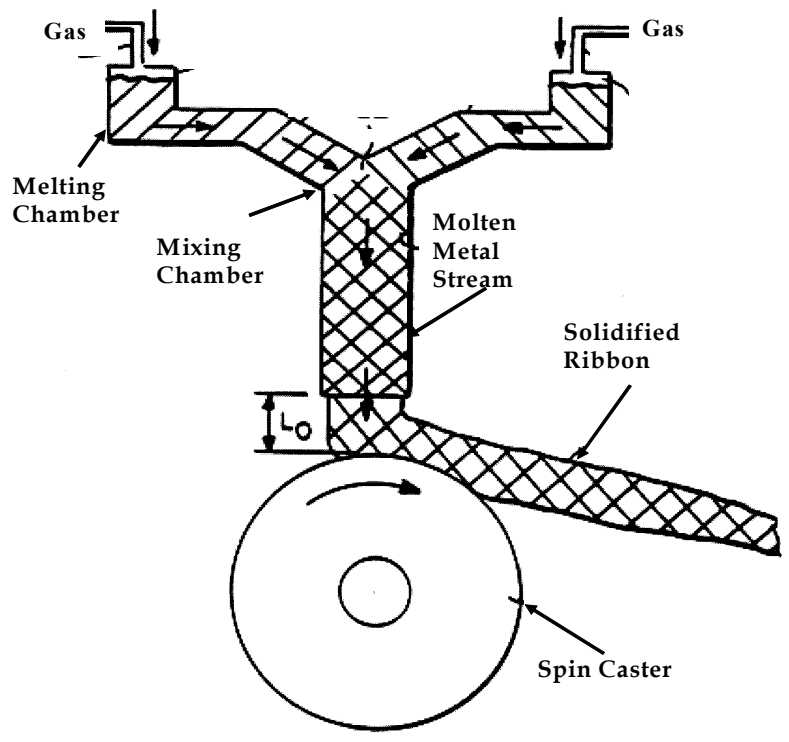

Fig. 6. Spin casting that rapidly solidifies the molten copper/titanium diboride Liquid Stream from the mixalloy equipment.

To control the matrix phase chemical composition, the flow rates must be controlled. We chose a pipe of a given diameter and varied the pressure of the reservoir of molten metals to control the mass flow rate. To assure that the cross-sectional area would not change during the ejection of molten metal because of freezing of copper at the wall, the pipes were kept at the melting point of copper, assuring isothermal flow of molten metals. It should be noted that we lost a year, since we tried to simplify the manufacture of the parts by just using a large pipe and allowing some freezing of the molten metal in the pipe, because some insisted that making a heated ceramic pipe for isothermal flow would be too costly. We ended up using 
isothermal delivery pipe maintained at the molten metal temperature for isothermal flow to create an uncoupled process.

To make a solid billet of the Mixalloy, the spin-cast Mixalloy in the form of a ribbon was chopped and put into a copper can, which was then compacted under hotisostatic (HIP) pressure and extruded.

Mixalloy Production Equipment had to be designed. Since we could not do a small scale experiment, we had to build the production equipment without any experience of laboratory experiments. Thus the final equipment designed and used in production is shown in Fig. 7. It consists of two pressure vessels in which the crucibles for molten metals are stored. A pipe connects the crucible to the impingement-mixing chamber, which is located between the two pressure vessels. The mixing chamber is connected to a nozzle, which controls the shape of the molten stream that casts on a spin caster. The spin caster is made of a pure copper disk with cooling channels inside to circulate cooling water to remove thermal energy from the caster. The caster rotates at high speeds. The cast Mixalloy freezes on the wheel quickly and flies off the surface of the caster, continuously exposing new copper disk surface for continuous casting.

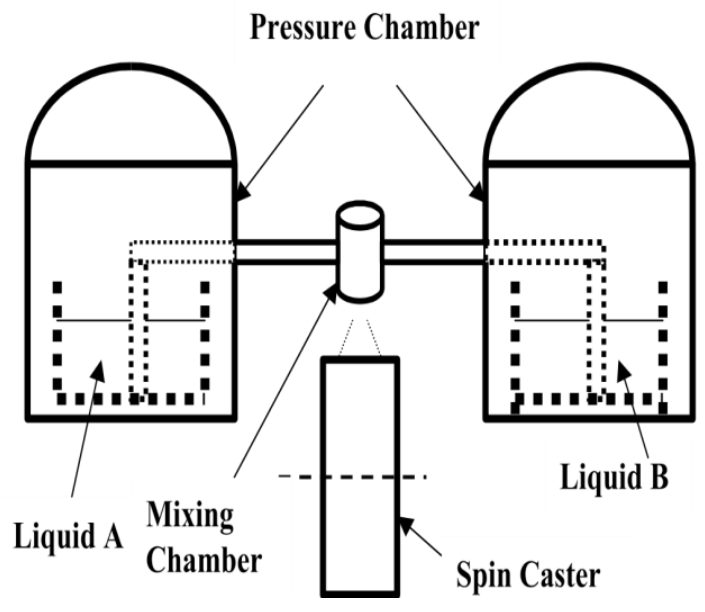

Fig. 7. A Schematic Drawing of the Mixalloying Equipment. The metal was melted using induction heating. The equipment was about 15 feet high and occupied an area about 20' x 20', excluding auxiliary equipment such as power supply, water tank, metal chip collectors, etc.

The first step in the process is to charge the crucible with copper and an alloying element (either titanium or boron). The charges are weighed exactly to minimize the possibility of having products that do not have the desired microstructure consisting of the pure copper phase and the ceramic phase. Then the metal is molten by induction heating. After the metal is completely molten, a small sample is taken out of the crucible to check its chemistry using mass spectroscopy. Then the vessel is closed, and the air in the pressure vessel is replaced with an inert gas. The pressure in the vessel is set to the desired pressure for a given volume of charge. When the valve is opened, the molten copper alloy is pushed out of the vessel by the gas pressure in the vessel. A continuous strip of Mixalloy is collected and sent out for consolidation by hot-isostatic pressure extrusion.

In less than four years from the decision to manufacture Mixalloy, without having done laboratory tests, we made the alloy and sold it to General Motors, Ford, and Chrysler as well as to automotive companies in Korea and Japan. However, we had to fold the commercial operation because the manufacturer of a competing product, a large company with deep pockets, kept lowering the price. A small start-up company with limited investment could not compete.

In conclusion, we were able to start with a theoretical idea, never tested through small-scale experiment, and engage in commercial operations in less than four years because we did not make a major mistake except the decision to use non-isothermal pipe, which made the process coupled. By recognizing that we should not have chosen what appeared to be an easy process soon enough to go back to an 
uncoupled design, we lost only about a year. Yet had we finished the project at least a year earlier, we could have saved valuable cash and the company might have been successful.

\section{Issues Related to Design and Implementation of Large Engineered Systems}

The key steps involved in developing large complex systems may be listed as follows:

Step 1: Identify the need or the problem to be solved.

Step 2: Create the key concept for the system's implementation through rational design.

Step 3: Secure sufficient funding to execute the large systems project.

Step 4: Execute the R\&D projects flawlessly.

Step 5: Do thorough analysis and simulation before making major commitments to hardware.

Step 6: Appoint competent people to key positions and create an organization around them.

Step 7: Receive certifications and permits as early as possible.

KAIST has had a unique opportunity to design and conduct research on two large multi-disciplinary systems projects that involved professors from many disciplines. This paper described and analyzed the processes involved in conceiving, designing, developing, and implementing large systems: OLEV, MH, and Mixalloy. This paper presented the design of the core technologies.

\subsection{Funding of large system projects}

Research and development of large complex systems requires significant funding, which is extremely difficult to obtain. This has been one of the major impediments to undertaking these projects at research universities (Suh, 2010b). Most funding agencies prefer to give small grants to many people rather than supporting a large systems project. They end up funding mostly analysis-oriented small projects rather than system-design-oriented large projects.

For OLEV, KAIST received about \$25 million in 2009 and \$15 million in 2010, and for MH, about $\$ 25$ million in 2009 and $\$ 10$ million in 2010, all from the government of the Republic of Korea. These extraordinary major grants were made possible by two events. In 2008, the author was the chairman of the Commission for Discovery of New Economic Growth Engines established by the Ministry of Knowledge Economy. As part of this effort, the author proposed the OLEV and the MH projects. He was also a member of the National Committee for Science and Technology, which gave him the opportunity to propose to President M. B. Lee of Korea that as part of the 2009 Supplementary Budget, Korea should undertake ten major innovative R\&D projects for two years so as to create technologies that could promote economic growth and create jobs. These suggestions resulted in the Supplementary Budget for science and technology, and KAIST received the funding for the OLEV and MH projects from the Supplementary Budget. What KAIST received was a small fraction (one-sixth) of the Supplementary Budget. Although there was a great deal of interest in the results of the two KAIST projects, not much is known about the results obtained from the other projects financed with the Supplementary Funding.

\subsection{Project execution}

KAIST started the OLEV project around January 2009, before receiving the funding on June 1, 2009. Initially one OLEV bus was built by converting a hybrid bus with the help of three industrial firms. Subsequently, four additional OLEV buses, one OLEV SUV, and one OLEV trackless trolley (without the overhead wire) were built. They were then certified by various government agencies for safety, noninterference with communications, etc. Since there were no existing regulations and specifications for OLEV, it took extraordinary effort to obtain the permits and certifications.

The concept for $\mathrm{MH}$ was conceived when I was walking around the Singapore Harbor with my wife in January 2007. I made the sketch of the concept in the airplane as we flew back to Korea. The MH project was officially started in March 2009. KAIST developed initial design concepts for MH and developed the underlying technologies for MH A1-250, the smallest Mobile Harbor, which carries 250 TEUs (TEU 
means "twenty-foot equivalent unit"). The basic technologies for the crane for MH A1-250 were also developed. A ship design company was engaged to design the floating parts of MH A1-250. Another ship design company designed larger floating platforms for mobile harbors $\mathrm{MH}$ A1-1200 and MH A1-700, using its existing software under the direction of the KAIST team. These designs were certified for seaworthiness by the Korean Register of Shipping (KR). The crane for these larger MHs was constructed by an industrial firm. A 1/3 model for MH A1-250 (height over $20 \mathrm{~m}$ and crane span of $25 \mathrm{~m}$ ) was built and successfully demonstrated in open sea.

\subsection{Role of analysis and simulation in system development}

Throughout the execution of these projects, coupling of functional requirements (FRs) of the system design was checked by developing a design matrix of the system at various levels of decomposition. Also, proposed designs were analyzed and simulated on computers to determine performance before we committed to construction of the equipment and devices. This ability to simulate performance prior to actual construction accelerated the progress of the projects. In many cases, modeling and analysis were not straightforward. The ultimate test of the simulation was the actual testing of the physical model.

\subsection{Organization of the project execution}

The OLEV and the MH projects had to be completed in two years because of the promises that were made in order to receive the special funding from the Supplementary Budget. The Directors of the OLEV project and the MH project were KAIST professors. There were about 90 members - professors, researchers and students -- engaged in each project. After the viability of the invention had been demonstrated, some of the tasks were subcontracted to industrial firms for actual construction. However, the KAIST teams developed most of the important technologies and directed the efforts of outside firms.

Participants in each project were organized in groups and teams to execute the high-level FRs. Group leaders were responsible for specific tasks. Most of group leaders were KAIST professors or researchers. During the first few months, I held one or two three-hour-long meetings every week. Most of the group leaders attended these meetings.

To be sure that there was no coupling of FRs, two separate teams checked the system architecture. They constructed the FR-DP decomposition trees and the design matrix to identify any coupling. Professors G. J. Park and T.S. Lee led the system architecture teams (Lee \& Park, 2010).

\subsection{Certification for public use}

OLEV and MH are used to transport people and goods. Therefore, many regulatory bodies had to approve the system and the product. The process of obtaining the permits took much longer than the development of the OLEV system, especially because there were no precedents for the OLEV technology. The process of obtaining any government certificates should begin as soon as possible in a given project. Numerous government agencies were involved in the approval of the OLEV systems, including the agency that approved the frequency spectrum to be sure that the OLEV system did not interfere with telecommunications. Many government agencies had to certify the safety of the systems under all weather and operating conditions.

\subsection{Intellectual property rights}

Since both of these projects involved highly innovative concepts and designs, we promptly applied for many patents to protect the technologies. Roughly 150 patents have been filed for the MH technology and 200 for the OLEV technology. We tried to secure strong patent positions to be sure that others would not infringe the rights to our technologies. We engaged two outside law firms for each project to apply for domestic and international patents. 


\subsection{Recognition of contributions by participants}

At universities, the intellectual contributions made by individual professors, staff, and students must be fully recognized. In large systems projects such as OLEV and $\mathrm{MH}$, we must make sure that all contributors are fully acknowledged by including their names in patent applications and by encouraging them to write research papers, individually or jointly with other collaborators, after the intellectual properties are properly protected.

\subsection{Detractors}

OLEV and $\mathrm{MH}$ are disruptive technologies that can eventually replace existing technologies (Christensen, 1997). Because these projects were highly visible in Korea, there were some detractors professors of electrical engineering, automotive engineers, politicians, etc. - who criticized the funding and interfered with the evaluation and funding process. Without even knowing anything about our specific designs, detractors ridiculed the projects and claimed that the proposed technologies could not be realized. These kinds of criticisms seem to support the notion that disruptive technologies go through three stages - ridicule, denial by experts, and acceptance - before they succeed (Parker, 2010). Although the best option is to ignore detractors if possible, it was necessary to counter their arguments by various means, which drained resources when the project had so many other tasks to perform. KAIST could overcome these obstacles because of its reputation and the technical progress made in a timely manner. Nevertheless, it is less than pleasant to deal with all sorts of false accusations and fabricated and intentional rumours. We tried to ignore most of them, but the intensity of these disruptions did not diminish for a long time.

\subsection{Technology transfer for commercialization}

Commercialization of disruptive technologies is a difficult but critical issue (Suh, 2010d). Investors tend to shy away from disruptive technologies because the perceived financial risk is large. For many disruptive technologies, the initial market size is extremely small and the return on investment is difficult to quantify. Therefore, large automobile companies and shipbuilding companies did not participate in the KAIST projects. However, a new venture firm was established in Korea and another one in the United States to commercialize OLEV under a license from KAIST. OLEV Korea has installed systems in Seoul Grand Park and at Expo 2012 in Yeosu, Korea. An OLEV system is to be installed in McAllen, Texas.

\section{Educational Issues}

Research universities have done an outstanding job in teaching analysis, but the education related to synthesis and design of systems has been lacking. At KAIST, we instituted bi-modal education concurrent teaching of analysis and synthesis - to make the student more creative. To achieve this goal, KAIST requires all freshmen to take the Freshman Design Course (FDC). After taking FDC, many students change their thought processes and learn to define the FRs before they tackle a problem (Thompson, 2010). They also understand the issues involved in systems design and develop appreciation for systems thinking.

KAIST also initiated the Renaissance Ph.D. Program, a bi-modal education program for graduate students. During the first two years of the five-year program, students learn design theories and actually design a complex system. Then, during the last three years of the program, they analyze and optimize their own designs. This is going to be a hallmark of KAIST education.

\section{Conclusions}

Many societal and industrial outputs are in the form of large complicated systems that must satisfy many different functional requirements within a set of constraints. The time and cost associated with innovation and development of these large systems can be significantly greater when ad hoc approaches 
based on experience and empiricism are used, rather than a theory-based approach, in designing and developing innovative products. What we have shown through the creation and innovation of major disruptive technologies - OLEV, MH, and Mixalloy - based on Axiomatic Design Theory is that we can bring about the desired results much more quickly and at lower costs than is possible under the current practice at many companies. Furthermore, these large systems that are based on the theory will always be more reliable and more readily serviceable than the systems created through ad hoc approaches used by many companies.

1) Two highly innovative systems - OLEV and MH - were conceived, designed, developed, and implemented at KAIST in the relatively short time period of two years. OLEV was selected as one of "The 50 Best Inventions of 2010" by TIME magazine. MH was selected as the second most promising start-up idea in "10 best start-up ideas of 2011" by StartupSmart, Inc. of Australia.

2) The Mixalloy project dealt with the development of a new metal alloy. It was also commercialized in less than four years. These three projects indicate that Axiomatic Design Theory has consistently enabled a rapid and reliable development of innovative technologies.

3) The execution of these projects demonstrates the importance of a systematic approach to design and development of innovative technologies. A sixteen-step process is presented that is important in development and implementation of large complex systems.

4) OLEV, SMFIR, and MH are disruptive technologies that can replace existing technologies.

5) Mixalloy had a limited market size, which made it difficult to compete against a large corporation.

6) The success of the OLEV and MH projects gives credence to the argument that government funds should be spent to support large innovative systems projects in addition to small, analysisoriented research projects.

7) Managers of Technology need to understand design theories as well as possess analytical capabilities.

\section{Acknowledgments}

It took a major commitment of funding by the Korean government to create two important disruptive technologies. Without the personal support of President M.B. Lee, we would not have created OLEV, SAMFIR, and MH. We thank him for his personal support of these projects. We are also indebted to National Assembly member J. S. Yoon and Minister Jae Won Park for their support. Our appreciation also goes to the officials in the Ministry of Education, Science and Technology, the Ministry of Planning and Strategy, and the Ministry of Knowledge Economy.

OLEV and SMFIR were successful because of the intellectual contributions of my colleagues at KAIST: Professors D.H. Cho, S. J. Jeon, J.H. Kim, C.T. Rim, I.S. Suh, Y. H. Jung, J. H. Yim, H. K. Lee, J. K. Kim, B. K. Park, and S. H. Chang of the OLEV team. The OLEV project was directed and headed by Professor D. H. Cho.

Professors B.M. Kwak, J.H. Oh, Y.S. Park, S.H. Kim, T.S. Lee, D. C. S. Ahn, K.S. Kim, I.G. Jang, Y.S. Park, S. H. Han, H. Chung, and P.S. Lee of the MH Team led and collaborated in these projects. Professor B. M. Kwak directed the MH team.

Professor J. H. Chun, Dr. Luis Sanchez, and Dr. Arthur Lee led the development of the Mixalloy technology, including the design and development of processing technologies and the equipment. They also opened the market for the new alloy.

I would like to express my personal appreciation to all those - faculty, staff, and students -- who worked with me in these projects. I am most grateful for their friendship, collegiality, dedication, and devotion to making these projects successful. 


\section{References}

Ahn, S., Pak, J., Song, T., Lee, H., Byun, J. G., Kang, D., Choi, C. S., Kim, E., Ryu, J., Kim, M., \& others. (2010). Low frequency electromagnetic field reduction techniques for the on-line electric vehicle $(O L E V)$. Paper presented at the IEEE Electromagnetic Compatibility Symposium.

Christensen, C. M. (1997). The innovator's dilemma : when new technologies cause great firms to fail. Boston, Mass.: Harvard Business School Press.

CNN. (2011). KAIST Online Electirc Vehicle Introduced by CNN. http://www.kaist.edu/english/01 about/06 news 01.php?req $P=$ bv\&req BIDX=10\&req BNM=ed news\&req_VI $=3422 \& r e q \_P C=90 \& r e q \_C G=\& s C A T E=\& s C H A R=$.

Kim, Y. Y., Choi, K. J., Chung, H., \& Lee, P. S. (2011). Axiomatic design study for automatic ship-toship mooring system for container operations in open sea. Oceans Systems Engineering, 1(2 ), $157-$ 169.

Lee, A. K., Sanchez-Caldera, L. E., Chun, J. H., \& Suh, N. P. (1988). Material with novel compositions and fine microstructljres produced via the Mixalloy process. Paper presented at the Material Research Society.

Lee, T., \& Park, G. J. (2010). Managing system design process using axiomatic design: a case on KAIST mobile harbor project. SAE International Journal of Material and Manufacturing, 3(1), 125-132.

Pachauri, R. K. (2007). Climate change 2007: synthesis report. Fourth Assessment Report of the Intergovernmental Panel on Climate Change.

Reuter. (2011). Mobile harbor delivers the goods for container ships at sea (video). http://www.reuters.com/video/2011/07/06/mobile-harbor-delivers-the-goods-forcon? videoId $=216843958$

Sanchez-Caldera, L. E., Suh, N. P., Chun, J. H., Lee, A. K., \& Blackall, F. S. (1987). Mixing and casting apparatus. Patent No. 4,706,730, U.S. Patent.

Sanchez-Caldera, L. E., Lee, A. K., Suh, N. P., \& Chun, J. H. (1990). Mixing and cooling techniques. Patent No. 4,890,662, U.S. Patent.

Sanchez-Caldera, L. E., Lee, A. K., Suh, N. P., \& Chun, J. H. (1991a). Dispersion strengthened materials. Patent No. 4,999,050, U.S. Patent.

Sanchez-Caldera, L. E., Lee, A. K., Suh, N. P., \& Chun, J. H. (1991b). Dispersion strengthened materials. Patent No. 5,071,618, U.S. Patent.

Suh, N. P. (1981a). Method for forming metal, ceramic or polymer compositions, Patent No. 4,278,622. U. S. Patent.

Suh, N. P. (1981b). Orthonormal processing of metals. Part I: concept and theory. Trans. ASME: Journal of Engineering for Industry 104(4), 327-331.

Suh, N. P., Tsuda, N., Moon, M. G., \& Saka, N. (1982). Orthonormal processing of metals. Part II: mixalloying process. Trans. ASME: Journal of Engineering for Industry 104, 332-338.

Suh, N. P. (1990). The principles of design. New York: Oxford University Press.

Suh, N. P. (2001). Axiomatic design: advances and applications. New York: Oxford Unversity Press.

Suh, N. P. (2005). Complexity: theory and applications. New York: Oxford University Press.

Suh, N. P. (2007). KAIST vision and mission. KAIST internal document.

Suh, N. P. (2008). Mobile harbor. Patent No. 10-2008-0041981, Korean Patent Office.

Suh, N. P., Cho, D. H., \& Rim, C. T. (2009). Power supply system and method for electric vehicle. pending.

Suh, N. P. (2009a). Patents on Mobile Harbor (MH). pending.

Suh, N. P. (2009b). Patents on on-line electric vehicle (OLEV). pending.

Suh, N. P. (2009c). Patent application. Patent No.10-2008-0041981, Korea Patent Office.

Suh, N. P., Cho, D. H., \& Rim, C. T. (2010). Design of on-line electric vehicle (OLEV). Paper presented at the CIRP Design Conference, Nante, France.

Suh, N. P. (2010a). Axiomatic design of large systems. Paper presented at the ASME 2010 International Design Engineering Technical Conference (IDETC), Montreal, Canada. 
Suh, N. P. (2010b). Electric vehicle for city transportation system. Patent No. 10-0940240, Korea Patent Office.

Suh, N. P. (2010c). Innovative engineering systems designed and developed at KAIST: OLEV and MH. Paper presented at the ASME 2010 10th Biennial Conference on Engineering Systems Design and Analysis (ESDA), Istanbul, Turkey.

Suh, N. P. (2010d). A theory of innovation and case study. International Journal of Innovation Management, 14(5), 893-893.

Suh, N. P., Chang, S. H., Cho, D. H., Cho, G. H., \& Rim, C. T. (2011). Power supply and acquisition device for on-Line electric vehicle. WO/2011/037434, WO Patent.

Suh, N. P. (2011a). Smart mobility: the future today. Paper presented at the The World Economic Forum, Davos, US.

Suh, N. P. (2011b). Design of wireless electric power transfer technology: shaped magnetic field in resonance (SMFIR). Paper presented at the 2011 CIRP Design Conference, Daejeon, Korea.

Suh, N. P. (2011c). Invention process, innovation continuum and case studies: OLEV, MH, and MuCell. Paper presented at the Hamlyn Symposium on Medical Robotics, London, UK (Invited Lecture).

Suh, N. P. (2011d). Transportation system using electric automobile. patent No. 0,153,184, U.S. Patent.

Thompson, M. K. (2010). Freshman design course at KAIST.

Time. (2010). The 50 best inventions of 2010.

Tucker III, C. L., \& Suh, N. P. (1980). Mixing for reaction injection molding: I. Impingement mixing of liquids. Polymer Engineering and Science, 20(13), 875-886.

Yang, D. Y., Lee, P. S., Chung, H., Kwak, B. M., \& Suh, N. P. (2009). Mobile harbor, loading and unloading. Application No. 10-2009-0045697, Korea Patent Office. 